\title{
Point-of-care Glucose Monitoring in COVID-19 Intensive Care Unit: How's It Different?
}

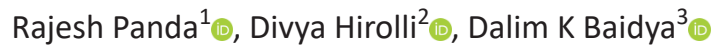 \\ Keywords: Blood glucose monitoring, COVID-19, Glucose control. \\ Indian Journal of Critical Care Medicine (2021): 10.5005/jp-journals-10071-24037
}

Sir,

Symptomatic coronavirus disease-2019 (COVID-19) patients commonly present with fever, cough, and shortness of breath which may ultimately lead to acute respiratory distress syndrome and severe hypoxia refractory to oxygen therapy. ${ }^{1}$ Based on available pieces of evidence, use of systemic corticosteroids is recommended for 7-10 days in severe and critical COVID-19 patients. However, steroids increase blood glucose levels by increasing hepatic gluconeogenesis, blocking the action of insulin and increasing insulin resistance, reducing uptake of glucose by the muscles and adipose tissue and it may even reduce the action of beta cells directly. Moreover, COVID-19 itself can cause new-onset diabetes in high-risk and susceptible population as an extrapulmonary complication and can worsen blood sugar control in those with preexisting diabetes. ${ }^{2}$ Hence, regular monitoring of blood glucose becomes crucial in the management of these patients.

Glucometers are simple, portable, and convenient blood sugar monitoring devices that are used for point-of-care management. This simple tool can at times be misleading if the sources of error in measurements are overlooked. There are a number of factors that can influence the accuracy of blood glucose strips. Altitude, temperature, oxygen concentration, hematocrit of the patient, triglyceride levels, blood levels of xylose, galactose, uric acid, and acetaminophen are among them. ${ }^{3}$ One such known source of error that is more commonly encountered in the COVID-19 intensive care unit (ICU) is the severe hypoxemia.

Widely there are two types of glucose strips available: glucose oxidase (GO) and glucose dehydrogenase (GDH) strips. In a GO strip, the enzyme GO interacts with the glucose in the blood and converts it into gluconic acid by accepting an electron. Now, this electron can be accepted either by oxygen and water to form hydrogen peroxide or by the specific oxidized mediator present in the strip which when accepts the electron passes it on to an electrode to generate a current that gets reported as glucose concentration. The mediator in the strip and the oxygen in the sample can both compete to take the electrons from the reduced $\mathrm{GO}$, but the electrode in the glucometer will only pick up the mediator to show the glucose levels. If the oxygen in the sample is higher, the active mediator will be proportionally lower leading to underestimation of glucose; vice versa, if the oxygen in the sample is lower, it can lead to overestimation of the glucose level. ${ }^{3}$ Blood glucose meters using the enzyme GO have been proven unreliable at high altitude for a similar reason. GDH blood glucose meters are likely to perform better than GO-based meters at high altitude as $\mathrm{GDH}$ is an oxygen-insensitive enzyme. ${ }^{4}$
${ }^{1}$ Department of Anesthesiology and Critical Care, AllMS, Bhopal, Madhya Pradesh, India

${ }^{2,3}$ Department of Anesthesiology, Pain Medicine and Critical Care, AlIMS, New Delhi, India

Corresponding Author: Divya Hirolli, Department of Anesthesiology, Pain Medicine and Critical Care, AllMS, New Delhi, India, Phone: +91 7795958685, e-mail: divyahirolli@gmail.com

How to cite this article: Panda R, Hirolli D, Baidya DK. Point-of-care Glucose Monitoring in COVID-19 Intensive Care Unit: How's It Different? Indian J Crit Care Med 2021;25(12):1465-1466.

Source of support: Nil

Conflict of interest: None

Unlike GO strips, the readings of GDH strips are not altered by the oxygen level in the sample. GDHs are the oxidoreductases that are unable to utilize oxygen as electron acceptors. The electron acceptors for GDH are cofactors like nicotine adenine dinucleotide, nicotine adenine dinucleotide phosphate, flavin adenine dinucleotide, or pyrroloquinoline quinone. There are different subtypes based on the cofactors used. These cofactors then pass on the electrons to an oxidized mediator present in the strip which when accepts the electron passes it on to an electrode to generate a current that gets reported as glucose concentration. ${ }^{5}$ The limitation of GO strips in giving an accurate glucose level value in varying oxygen concentrations can be overcome by the GDH glucose strips.

Thus, GDH strips should be preferred in measuring bedside blood sugar levels in COVID-19 ICU as most of the patients are hypoxemic and are likely to have a high glycemic variability.

\section{OrCID}

Rajesh Panda @ https://orcid.org/0000-0001-7123-876X

Divya Hirolli @ https://orcid.org/0000-0001-6213-300X

Dalim K Baidya @ https://orcid.org/0000-0001-7811-7039

\section{References}

1. Johnson KD, Harris C, Cain JK, Hummer C, Goyal H, Perisetti A. Pulmonary and extra-pulmonary clinical manifestations of COVID-19. Front Med (Lausanne) 2020;7:526. DOI: 10.3389/fmed.2020.00526.

2. Sosale A, Sosale B, Kesavadev J, Chawla M, Reddy S, Saboo B, et al. Steroid use during COVID-19 infection and hyperglycemia-what a physician should know. Diabetes Metab Syndr 2021;15(4):102167. DOI: 10.1016/j.dsx.2021.06.004.

3. Ginsberg BH. Factors affecting blood glucose monitoring: sources of errors in measurement. J Diabetes Sci Technol 2009;3(4):903-913. DOI: $10.1177 / 193229680900300438$.

() The Author(s). 2021 Open Access This article is distributed under the terms of the Creative Commons Attribution 4.0 International License (https://creativecommons. org/licenses/by-nc/4.0/), which permits unrestricted use, distribution, and non-commercial reproduction in any medium, provided you give appropriate credit to the original author(s) and the source, provide a link to the Creative Commons license, and indicate if changes were made. The Creative Commons Public Domain Dedication waiver (http://creativecommons.org/publicdomain/zero/1.0/) applies to the data made available in this article, unless otherwise stated. 
4. Öberg D, Ostenson CG. Performance of glucose dehydrogenaseand glucose oxidase-based blood glucose meters at high altitude and low temperature. Diabetes Care 2005;28(5):1261. DOI: 10.2337/ diacare.28.5.1261.
5. Ferri S, Kojima K, Sode K. Review of glucose oxidases and glucose dehydrogenases: a bird's eye view of glucose sensing enzymes. JDiabetes Sci Technol 2011;5(5):1068-1076. DOI: $10.1177 / 193229681100500507$. 